\title{
CONGENITAL ADRENAL HYPERPLASIA IN MONOZYGOTIC TWINS WITH VARIABLE CLINICAL MANIFESTATIONS*
}

\author{
Debasis KanjILal, ${ }^{1}$ Ram S. Verma, ${ }^{2, * *}$ Leonard Glass, ${ }^{1}$ Arvind Babu, ${ }^{3}$ \\ Fatih Ramazanoglu, ${ }^{1}$ and Serpouhi PoPeSCU ${ }^{3}$ \\ ${ }^{1}$ Department of Pediatrics, Suny Health Science Center, \\ Brooklyn, N.Y. 11203 \\ ${ }^{2}$ Division of Genetics, Long Island College Hospital, Suny Health Science Center, \\ Brooklyn, N.Y. 11201 \\ ${ }^{3}$ Division of Medical Genetics, Beth Israel Medical Center, Mt. Sinai School of Medicine, \\ New York, N.Y. 10003
}

\begin{abstract}
Summary The first cases of congenital adrenal hyperplasia III with variable clinical manifestations in female monozygotic twins are presented. Twin "A" revealed severe hypertrophy of the clitoris, labial fusion and a visible introitus. However, twin " $B$ " manifested moderate clitoral hypertrophy, a visible introitus and no labial fusion. Neither infant had palpable gonads.
\end{abstract}

\section{INTRODUCTION}

Congenital adrenal hyperplasia is an autosomal recessive disorder caused by decreased activity of one of the enzymes required for the synthesis of cortisol (Gala et al., 1969). In the vast majority of cases, the enzyme involved is 21 -hydroxylase (P450C21) (McKusick, 1987). This defect leads to a negative feed back mechanism, causing an increased secretion of adrenocorticotropic hormone (ACTH), which in turn, stimulates an increased production of adrenal and androgenic hormones (White et al., 1987a).

The affected female fetus undergoes masculinization to varying degrees, depending on the severity of the enzyme deficiency. In severe cases, aldosterone production is affected, with subsequent increased urinary sodium loss, hyperkalemia, dehydration, shock and possible death (White et al., 1987b; New et al., 1981; Murtaza et al., 1980; Miller and Levine, 1987).

In monozygotic twins with this disorder, one would expect the degree of mas-

Received February 28, 1989; revised version received July 18, 1989; Accepted August 3, 1989.

* Presented at 39th Annual Meeting of the American Society of Human Genetics, San Diego, 1987.

** Request reprints from: Prof. Ram S. Verma, Chief Division of Genetics, Long Island College

Hospital, 340 Henry St., Brooklyn, N.Y. 11201, USA 
culinization to be similar. In this report, we are presenting the first reported cases of monozygotic twins exhibiting significantly variable clinical manifestations.

\section{CASE REPORT}

Twin girls were delivered vaginally to a healthy 23 year old black woman after an uneventful 40 week gestation. Their weights were $3,267 \mathrm{~g}$ (Twin A) and 3,100 $\mathrm{g}$ (Twin B). There were separate diamniotic, dichorionic, placentas. The parents were unrelated and there was no significant family history.

Physical examination of Twin A revealed severe clitoral hypertrophy, labial fusion, and a visible introitus. Twin B manifested moderate clitoral hypertrophy, a visible introitus, and no labial fusion (Fig. 1). Neither infant had palpable gonads. Clinical and laboratory findings of both twins are shown in Table 1. Both neonates were asymptomatic at birth, and routine hematologic and biochemical studies were normal. Serum 17-OH progesterone concentrations however, were elevated in both children (Table 1). Serum adrenocorticotropin concentrations were not measured. A clinical diagnosis of congenital adrenal hyperplasia was made, and the infants were treated with physiologic doses of cortisone acetate. Investigations of blood types and subtypes, were performed and were identical, in-
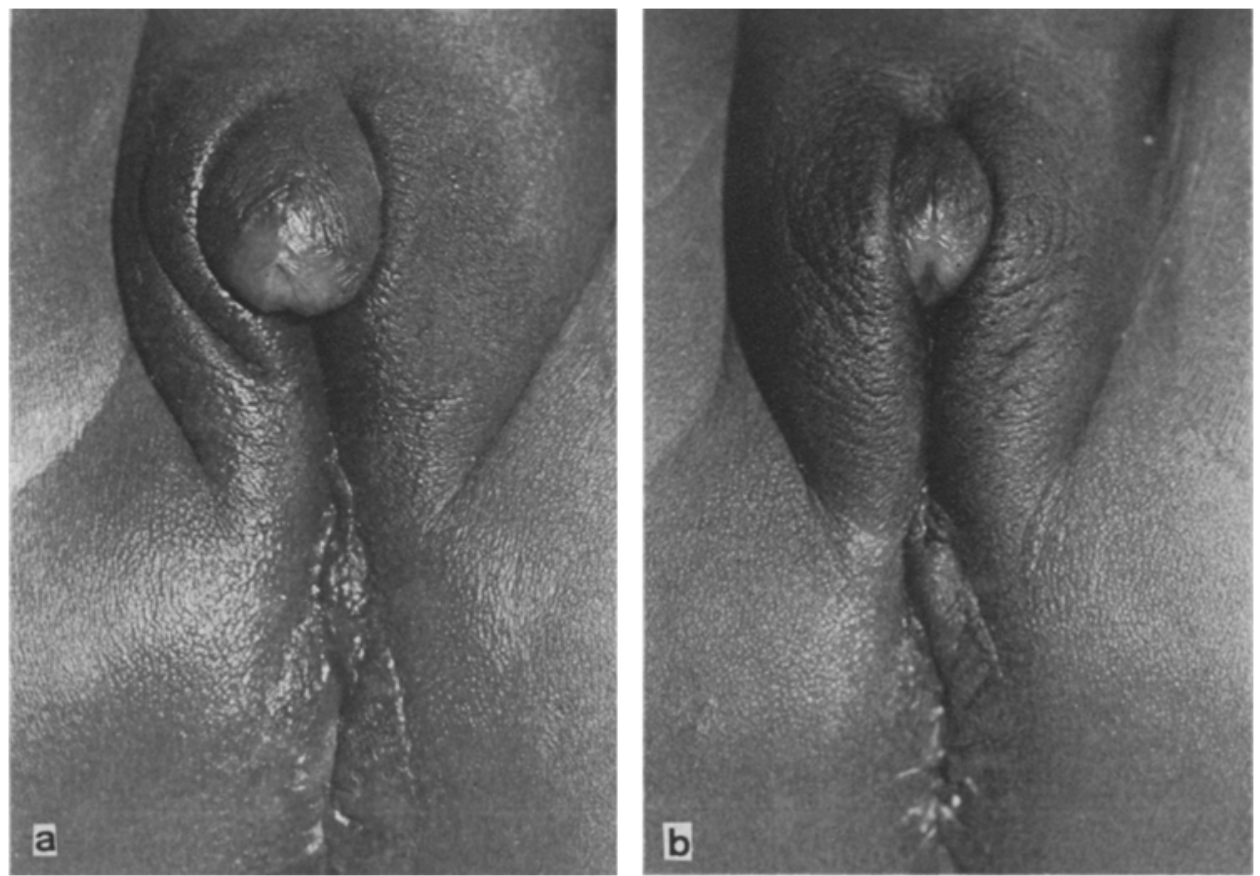

Fig. 1a. Severe clitoral hypertrophy in twin A.

1b. Moderate clitoral hypertrophy in twon B. (Absence of labial fusion.) 
Table 1. Clinical and laboratory findings.

\begin{tabular}{lcc}
\hline Features & Twin A & Twin B \\
\hline Birth weight & $3,265 \mathrm{~g}$ & $3,100 \mathrm{~g}$ \\
Genitalia & +++ & ++ \\
$\quad$ Hypertrophied clitoris & + & - \\
$\quad$ Labial fusion & + & ++ \\
$\quad$ Visible introitus & - & - \\
$\quad$ Palpable gonad & ++ & + \\
$\quad$ Visible urethral orifice & $46, \mathrm{XX}$ & $46, \mathrm{XX}$ \\
Karyotype & $5.2 \mu \mathrm{g} / \mathrm{liter}$ & $9.8 \mu \mathrm{g} / \mathrm{liter}$ \\
Serum 17 OH progesterone & $21 \mathrm{mmol} / \mathrm{liter}$ & $27 \mathrm{mmol} / \mathrm{liter}$ \\
Urine Na & Normal & Normal \\
Serum electrolytes & ++ & + \\
Visible uterus by Sonogram & &
\end{tabular}

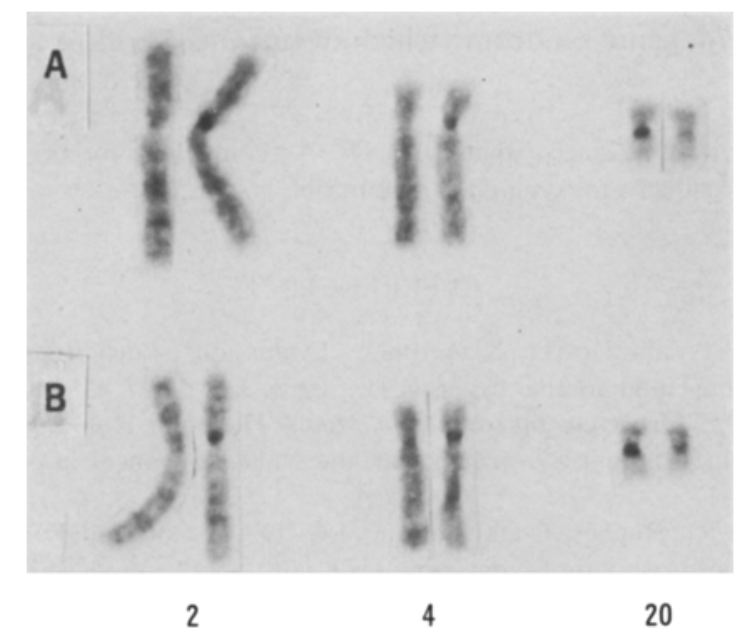

Fig. 2. Partial karyotype of twins showing highly "rare" heteromorphic markers on chromosomes 2,4 and 20 by restriction endonuclease AluI confirming monozygosity of twins.

dicating the monozygotic origin of the twins. Chromosomal preparations for karyotyping were made from PHA-stimulated cultures of peripheral blood lymphocytes and various banding techniques were applied (Verma and Babu, 1989). Cytogenetic findings for both twins were $46, \mathrm{XX}$. Heteromorphic markers were evaluated utilizing restriction endonucleases AluI, and were found to be identical, thus confirming monozygosity (Fig. 2). Neither of the twins was found to be a salt loser. 


\section{DISCUSSION}

Because of separate placentation and significant differences of virilization, it was our initial clinical impression that our patients were dizygotic twins. We were, however, able to demonstrate monozygosity using standard blood typing and a restriction endonuclease technique.

Differences in secretion of adrenocorticotropin and androgenic steroids, and/or end organ response during critical periods in gestation are possible explanations for the dissimilar degrees of virilization. It is, however, interesting to note that the postnatal serum concentration of 17-hydroxyprogesterone in the moderately affected twin was approximately twice that of the severely affected infant.

These cases suggest that non-genetic factors may play a role in the degree of virilization of female fetuses with 21 hydroxylase deficiency. Alternatively, the affected enzymes may not be absent or deficient but functioning poorly. It has been demonstrated that monozygotic twins with double placentation, while genetically identical, may have dissimilar phenotypic characteristics. Future investigations using advanced technology may unmask many details about the molecular basis of these steroidogenic syndrome which in turn may lead to a better application of therapy.

Acknowledgments Our sincere thanks to Dr. Anthony Botti for providing clinical review of the case and Sonia Williams for typing the manuscript.

\section{REFERENCES}

Gala, O.M., Rudd, B.T. and Drayer, N.M. 1969. Evaluation of deficiency of 21-hydroxylation in patients with congenital adrenal hyperplasia. Arch. Dis. Child. 43: 410-414.

McKusick, V.A. 1987. Mendelian Inheritance in Man, The John Hopkins Press, Baltimore.

Miller, W.L. and Levine, L.S. 1987. Molecular and clinical advances in congenital hyperplasia. J. Pediatr. 111: 1-17.

Murtaza, L., Sibert, J.R., Hughes, I. and Balfour, I.C. 1980. Congenital adrenal hyperplasia-a clinical and genetic survey: are we detecting male salt losers? Arch. Dis. Child. 55: 662-625.

New, M.I., Dupont, B., Pollack, M.S. and Levine, L.S. 1981. The biochemical basis for genotyping 21-hydroxylase deficiency. Hum. Genet. 58: 123-127.

Verma, R.S. and Babu, A. 1989. Human Chromosomes (Manual of Basic Techniques), Pergamon Press, New York.

White, P.C., New, M.I. and Dupont, B. 1987a. 1. Congenital adrenal hyperplasia. New Eng!. J. Med. 316: 1519-1524.

White, P.C., New, M.I. and Dupont, B. 1987b. I1. Congenital adrenal hyperplasia. New Engl. J. Med. 316: 1580-1586. 